\title{
LEVANTAMENTO ATUAL E HISTÓRICO DE OCORRÊNCIAS DE DESASTRES RELACIONADOS A EVENTOS GEODINÂMICOS NA REGIÃO METROPOLITANA DE CAMPINAS COM BASE EM MÍDIA IMPRESSA E DIGITAL
}

\author{
Luiz Eduardo Gonçalves ${ }^{(a)}$, Cláudio José Ferreira ${ }^{(b)}$, Jefferson de Lima Picanço ${ }^{(\mathrm{c})}$ \\ (a) Instituto de Geociências, Universidade Estadual de Campinas, [luizgoncalves_pb@hotmail.com] \\ (b) Instituto Geológico, Secretaria do Meio Ambiente do Estado de São Paulo, [cjfcjf@gmail.com] \\ (c) Instituto de Geociências, Universidade Estadual de Campinas [jeffpicanco@gmail.com]
}

\section{Eixo: GEOGRAFIA FÍSICA E DESASTRES NATURAIS}

\begin{abstract}
Resumo
Buscando elaborar um levantamento atual e histórico de registros jornalísticos de desastres relacionados a eventos geodinâmicos na Região Metropolitana de Campinas (RMC), as atividades do projeto consistiram em: (A) "Levantamento de notícias de jornais e de sites na Internet nas formas impressas e digitais", que tratou-se de uma longa pesquisa em bancos de dados em formato eletrônico que continham informações de variadas fontes. Concomitantemente a essa atividade, buscou-se elaborar uma (B) "Padronização dos registros de eventos e locais sob a forma de banco de dados no programa Excel em que trabalhou-se na criação de uma planilha". Posteriormente a isso se executou uma (C) "Espacialização dos registros obtidos", através da elaboração de mapas geolocalizados. Atualmente o banco de dados conta com 833 registros de eventos e a partir dele foi possível elaborar análises significativas sobre o histórico na ocorrência de eventos geodinâmicos na RMC.
\end{abstract}

Palavras chave: RMC; DESASTRES GEODINÂMICOS; NOTÍCIAS JORNALÍSTICAS.

\section{Introdução}

No contexto de uma crescente população urbana e uma ocupação desordenada do espaço urbano, a ocorrência de acidentes envolvendo eventos geodinâmicos na RMC nos últimos anos tem sido recorrente, em decorrência de diversos processos naturais, tais como: inundações, escorregamentos e vendavais. Esses fenômenos acarretam inúmeros transtornos aos habitantes dessas localidades, com prejuízos que afetam tanto o âmbito econômico, como o social. Considerando esse panorama e partindo do princípio que a RMC, apesar de ser um polo científico e tecnológico do estado de São Paulo e concentrar uma população de mais de três milhões de habitantes (IBGE, 2015), ainda não possui levantamentos históricos unificados e recentes nessa temática, buscou-se catalogar incidências dos eventos em uma análise atual e histórica dos últimos 20 anos dos eventos registrados.

A criação de bancos de dados de eventos geodinâmicos utilizando-se os softwares como o Excel e Google Drive, tendo como fontes de informação registros jornalísticos (impressos e digitais) é uma estratégia que 
possui grande potencial para administração pública implantar medidas efetivas, que tenham como objetivo impedir ou ao menos amenizar eventos futuros. Afirma-se isso partindo do princípio de que esse procedimento constitui um método de baixo custo, fácil atualização e que é capaz de fornecer resultados significativos sobre: áreas críticas, principais fenômenos que afligem a área e períodos do ano em que há mais probabilidade de determinados eventos (FERREIRA et al., 2011).

Dessa forma, o objetivo desse estudo foi catalogar incidências de eventos geodinâmicos na RMC, buscando o entendimento da forma dos seus padrões atuais por meio de uma análise histórica dos acontecimentos.

\section{Metodologia}

Procurando atingir esse objetivo, as atividades desenvolvidas constituíram-se em: a) coleta de notícias relacionada aos desastres na área de estudo em fontes jornalísticas diversas; b) organizar as informações por meio de um software que facilite o armazenamento e consulta de dados; c) espacializar os registros catalogados em mapas geolocalizados. A partir disso, como resultado, foi possível gerar um panorama dos problemas deflagrados pelos eventos geodinâmicos que afligiram a área.

Para a elaboração do levantamento histórico-atual de eventos geodinâmicos da RMC, os registros foram coletados em fontes diversas, sobretudo em notícias publicadas em meios eletrônicos disponíveis na internet, como Correio Popular, G1 Campinas e Região e também em bancos de dados pré-existentes, como o Banco de Dados de Desastres Naturais do Instituto de Pesquisas Meteorológicas (IPMet) (PELLEGRINA, 2012), o acervo de registros do Corpo de Bombeiros do município de Campinas localizado no Centro de Memória da UNICAMP (CMU), o Banco de Dados de Registros de Desastres da Defesa Civil (Sistema Integrado de Informações sobre Desastres - S2ID), que possuem informações provenientes da Defesa Civil, e o Cadastro de desastres de eventos geodinâmicos no Estado de São Paulo no período de 2010-2015 (NUNES e FERREIRA, 2015), que utiliza fontes variadas de informações, tais como: mídia eletrônica, a sistematização dos registros do SIDEC (Sistema Integrado de Defesa Civil) da CEDEC (Coordenadoria Estadual de Defesa Civil), os atendimentos em situações de emergência realizados pelo Instituto Geológico durante a Operação do PPDC (Plano Preventivo de Defesa Civil).

O banco criado conta com 833 registros de eventos coletados durante o intervalo de vigência do projeto (setembro 2015 - julho 2016). Esses registros viabilizaram a elaboração de algumas análises referentes ao panorama histórico e atual de ocorrência de eventos na Região Metropolitana de Campinas (RMC), tais como: áreas com um histórico de ocorrência e fenômenos mais recorrentes. 
Numa análise aos eventos contabilizados com o auxílio da tabela de Classificação e decodificação Brasileira de Desastres foi possível constatar que a maior parte dos eventos registrados pertence ao grupo de desastres meteorológicos: tempestades, chuvas intensas, raios granizo, etc. (58\%) e hidrológicosinundações, alagamentos, enxurradas, etc. (28\%), somente esses dois grupos reúnem cerca de $86 \%$ dos eventos. Entretanto, deve-se destacar também a significativa presença e eventos do grupo Climatológicoseca, estiagem e incêndio florestal (10\%) e em menor ocorrência o Geológico- deslizamentos, subsidência/colapso, etc. (4\%). A análise gráfica dessa variável pode ser observada na Figura 1.

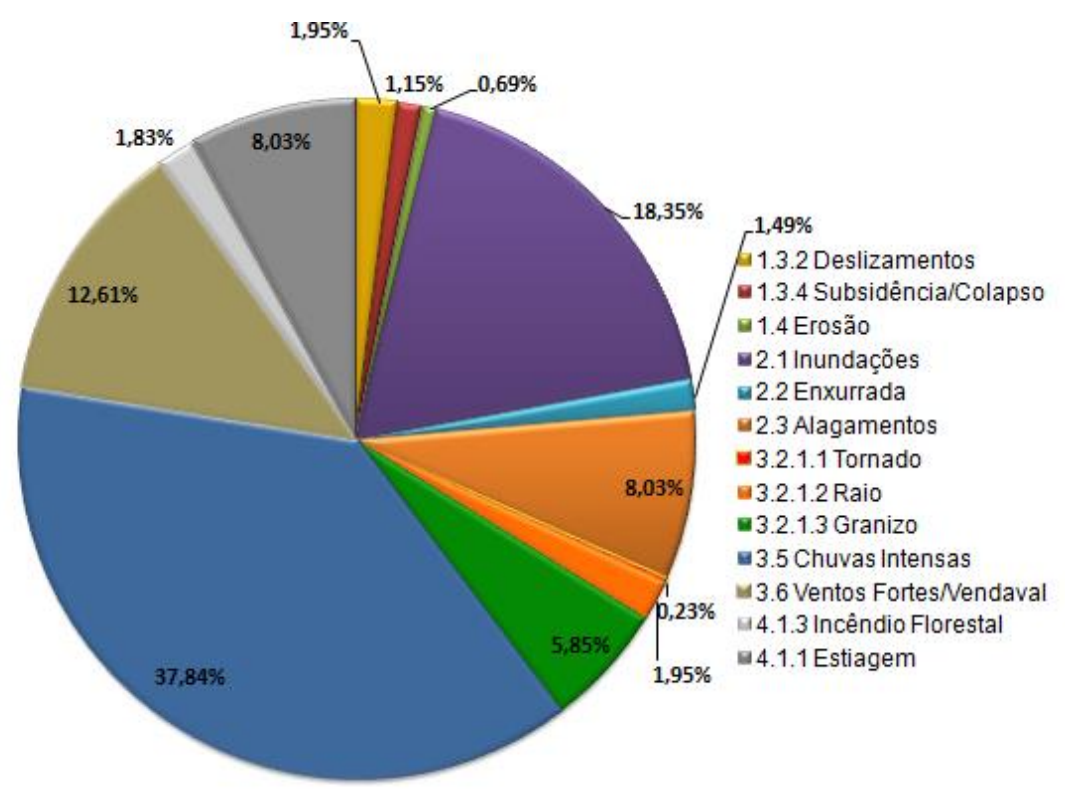

Figura 1- Tipos de Eventos em Relação ao Total de Registros organizados de acordo com a Classificação e Codificação Brasileira para Desastres (COBRADE).

Utilizando os registros presentes no banco de dados gerado também foi possível criar um mapa geolocalizado (Figura 2) dos eventos registrados no município de Campinas nos últimos 20 anos. Optouse por aplicar esse método de análise somente ao município de Campinas em virtude de ser o município com maior número de registros no banco de dados criado, o que permitiu a obtenção de um mapa mais abrangente. Apesar de a maior parte dos registros não possuir uma localização precisa dos eventos através de coordenadas, a execução dos mapas foi possibilitada por meio da utilização do software online de criação de mapas do GoogleDrive $®$ My Maps, que oferece uma coordenada aproximada a partir da inserção de dados como a rua e/ou bairro em que houve a ocorrência. 

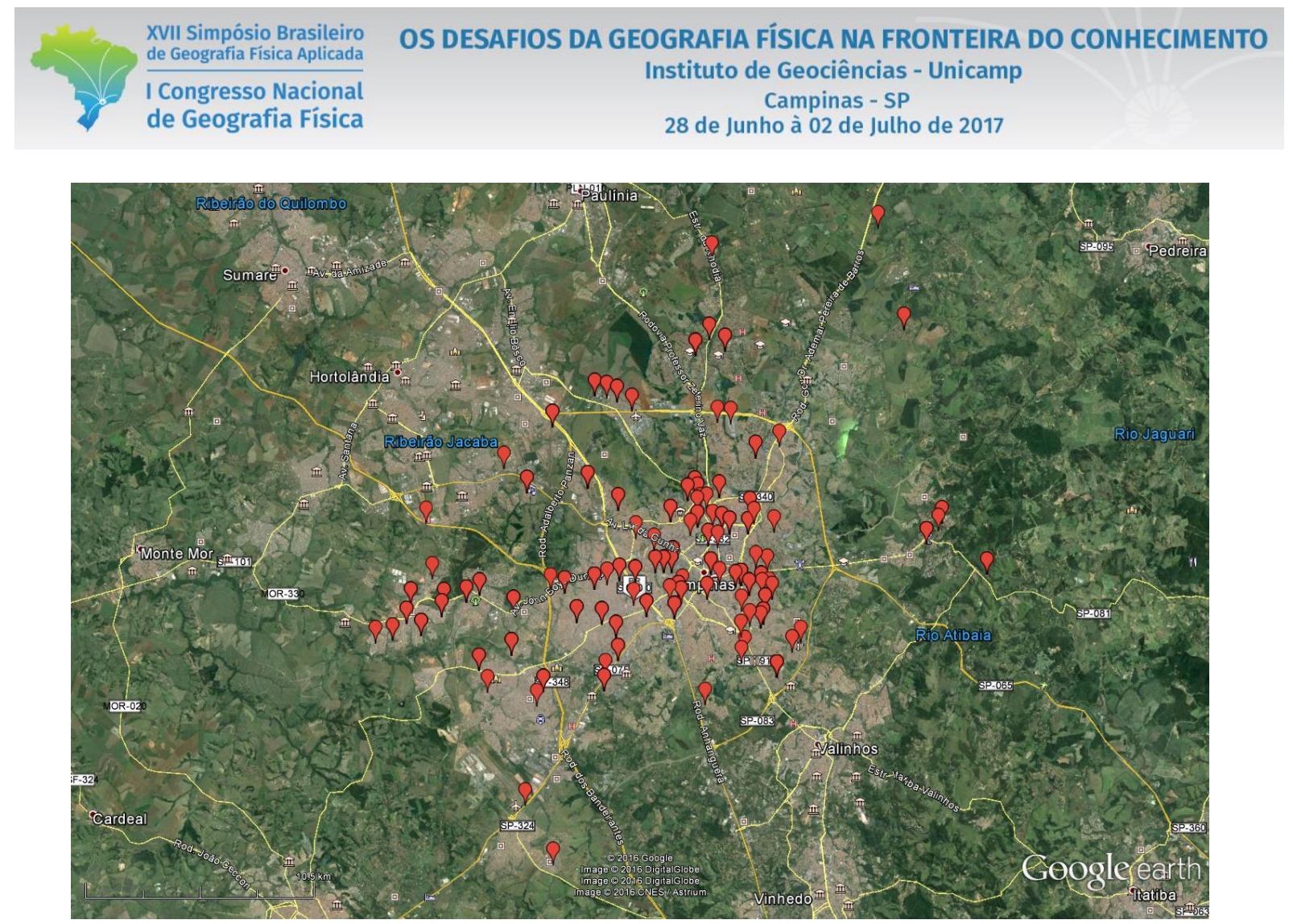

Figura 2 - Mapa de localização dos eventos registrados no município de Campinas-SP.

Para se traçar um panorama da relevância dos resultados obtidos através do projeto, realizou-se uma análise comparativa entre o número de registros levantados por essa pesquisa e o número de eventos registrados pelo Emergency Events Database-EM-DAT (Below et al., 2009), um banco de dados desenvolvido e administrado pelo Centre for Research on the Epidemiology of Disasters (CRED) da Universidade de Louvain, na Bélgica.

Foi realizada uma pesquisa no EM-DAT, selecionando-se o período que o projeto abrangeu (1995 a 2016) e a localização, que no caso desse banco é possível somente selecionar o país (Brasil). A partir desses procedimentos, chegou-se ao resultado de 58 eventos registrados nesse período no Brasil, enquanto nesse projeto registrou-se um total de 833 eventos somente para a RMC, ou seja, foi possível evidenciar um déficit significativo nos dados fornecidos por essa ferramenta. Entretanto, deve-se levar em conta, que o EM-DAT não contabiliza eventos de pequeno porte, tal como foi a metodologia adotada nesse projeto e defendida por SAITO et al. (2009) e outros (SOUZA \& SANT'ANNA NETO, 2004, DANNI-OLIVEIRA et al., 2004; HERRMANN et al., 2004), porém, ainda assim deve-se atentar para a relevância dos dados obtidos, visto que a partir do registro desses eventos há a possibilidade de se estabelecer um retrato mais fiel da realidade enfrentada nas localidades. Tendo por base isso, o grande déficit que há, pode ser um grande viés para a elaboração de políticas públicas efetivas na prevenção de eventos geodinâmicos. 


\section{Considerações Finais}

A partir dos resultados obtidos no desenvolvimento do projeto, foi possível desenvolver interpretações significativas sobre a ocorrência, distribuição e efeitos de eventos geodinâmicos na RMC, uma região que até então não possuía um estudo nesse âmbito com essa escala de análise. A partir desse projeto, também foi possível comprovar-se que a utilização de registros midiáticos para a obtenção de dados estatísticos sobre desastres, diz respeito a um método bastante eficiente por ter proporcionado análises que poderão ser utilizadas para a elaboração de políticas públicas eficientes e de ações efetivas na prevenção de futuros eventos.

\section{Bibliografia}

EM-DAT- The OFDA/CRED International Disaster Database. Disponível em: <http://www.emdat.be/database> Acesso em: 15 jul. 2016

FERREIRA, C. J. ; OGIHARA, V. H. ; VIEIRA, R. E. ; BIGANZOLLI, R. . Uso da mídia eletrônica na elaboração de banco de dados de desastres relacionados a eventos geodinâmicos no Estado de São Paulo. In: Congresso Brasileiro de Geologia de Engenharia, São Paulo, 2011. Anais. São Paulo: Associação Brasileira de Geologia de $\quad 2011 . \quad$ p. $1-6 . \quad$ Disponível emharia, https://drive.google.com/open?id=0B0J5AK7clDOaZjgzNTUzMTYtNmRIMy00YWVmLTk2NzMtMDQzNjBmZjE 3YWU4\&authuser=0 Acesso em: 14 jul. 2016

NUNES, R.G.S.; FERREIRA, C.J.; Cadastro de desastres e eventos geodinâmicos no Estado de São Paulo no período de 2010-2015. GEOSUDESTE 2015, Campos do Jordão (SP)-Out/ 2016. p. 1-5. Disponível em: https://www.researchgate.net/publication/283422322_Cadastro_de_desastres_e_eventos_geodinamicos_no_Estado_ de_Sao_Paulo_no_periodo_2010-2015 Acesso em: 15 jul. 2016

PELLEGRINA, G. J. Variabilidade climática, desastres naturais e a relação com eventos severos no estado de São Paulo. CLIMEP. Climatologia e Estudos da Paisagem, Rio Claro (SP) - Vol.7 - n.1-2 - janeiro/dezembro/2012, p. $46-72$. 